\title{
DSM I, II, III, IV, 5 (1952 - 2013)
}

Pedro M. Teixeira*

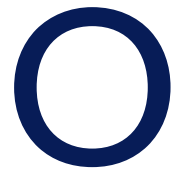

anúncio foi feito a 29 de Abril de 2013, duas semanas antes do lançamento da versão 5 do Diagnostic and Statistical Manual of Mental Disorders (DSM-5): o National Institute of Mental Health (NIMH) não irá financiar mais o DSM. Esta é a sua última versão. Como o casal que anuncia que não terá mais filhos duas semanas antes do nascimento do seu quinto filho; com o parto, as atenções focam-se no bebé e o anúncio prévio fica esquecido. A notícia da publicação do novo manual, desta vez '5' e não 'V', fez com que a comunicação do seu fim passasse despercebida. Porque terminou o financiamento ao DSM? Nas palavras do presidente do NIMH, Thomas Insel (2013):

The strength of each of the editions of DSM has been "reliability"-each edition has ensured that clinicians use the same terms in the same ways. The weakness is its lack of validity. Unlike our definitions of ischemic heart disease, lymphoma, or AIDS, the DSM diagnoses are based on a consensus about clusters of clinical symptoms, not any objective laboratory measure. In the rest of medicine, this would be equivalent to creating diagnostic systems based on the nature of chest pain or the quality of fever. Indeed, symptom based diagnosis, once common in other areas of medicine, has been largely replaced in the past half century as we have understood that symptoms alone rarely indicate the best choice of treatment. Patients with mental disorders deserve better.

No lançamento das versões anteriores houve sempre debate em torno das categorias de classificação propostas e grande agitação em torno do uso do DSM. ${ }^{1-3}$ Desde 1952 várias categorias entraram e saíram da classificação de perturbação mental (e.g. homossexualidade). Por se tratar de um acordo sobre sintomas clínicos, o que é valorizado ou não como sintoma clínico, assim como a obtenção de um consenso, resulta de apreciações que ocorrem num dado contexto histórico nas suas dimensões sociais, políticas e culturais.

* Pedro M. Teixeira, PhD. Psicólogo, Investigador no Núcleo de Saúde Comunitária do Instituto de Investigação em Ciências da Vida e da Saúde, da Escola de Ciências da Saúde da Universidade do Minho.
A validade do DSM sempre foi questionada apesar de se considerar uma referência fiável. Como pode o que não é válido ser considerado fiável? Apenas porque se generalizou o seu uso e se ganhou uma sensação, porventura falsa, de que se estão a usar os mesmos termos com os mesmos significados? A consistência na possibilidade de erro (não validade) não deveria ser percebida como fiabilidade. Quem confia numa mercearia que vende cebolas pesadas através de uma fita métrica? Se ela o faz há 60 anos haverá quem confie, decididamente.

O DSM tem sido percebido como fiável apesar da sua validade duvidosa. E talvez por isso, para alguns, o anúncio da morte do DSM seja precoce e exagerado. A quinta versão foi editada há dois anos e continua a ser leccionada e utilizada como referência por profissionais 'Psi' e não só. E assim continuará por muitos anos, apesar de não estar também esta versão 5 isenta de polémica. ${ }^{4}$

Alguns pontos que merecem atenção prendem-se com a patologização de aspectos da vida quotidiana, como a inclusão do luto como transtorno depressivo, ou do esquecimento próprio da terceira idade como transtorno neurocognitivo menor, ou das preocupações do dia-a-dia como perturbação de ansiedade ou, ainda, a inclusão do uso intensivo de internet ou do sexo com muita frequência como novas adições comportamentais. Também a revisão nas definições de Autismo, de Perturbação de Stress Pós Traumático, de Défice de Atenção e no Abuso de Substâncias têm suscitado várias reacções e críticas. É particularmente crítico o uso destas classificações para efeitos de intervenção em educação quando não é esse o seu propósito.

Na ausência de uma alternativa, as categorias DSM, ou as do congénere ICD10, continuarão a ser usadas como referenciais de classificação para efeitos práticos de diferenciação, seja para prescrição, para benefício social ou para constrangimento legal. Não se vislumbra o seu abandono sem uma alternativa.

O que virá a seguir? Thomas Insel responde com o projecto Research Domain Criteria (RDoC) que lançará 
as fundações de um novo sistema de classificação, incorporando 'genetics, imaging, cognitive science, and other levels of information. Um olhar mais atento ao projecto (informação disponível em: http://www.nimh. nih.gov) sugere que o pêndulo do biopsicossocial será agora puxado para o nível individual focado no fisiológico, no genético e no neurológico. O referencial conceptual parece ignorar a forte evidência de factores causais, como: pobreza, desemprego e trauma. Ao ignorar a relação transaccional da pessoa com múltiplos níveis contextuais apresenta-se, para já, como um referencial que assenta numa epistemologia reducionista. Um regresso ao passado cuja projecção no futuro se alicerça nas expectativas de resultados decisivos graças às inovações da genética e da neurologia.

O fim anunciado do DSM sugere um óbito e, como tal, pede um requiem. Até porque, quanto ao futuro, já diz o ditado: 'depois de mim virá quem de mim bom fará'. Muitas questões ficam ainda sem resposta. ${ }^{5} \mathrm{Im}$ porta lançar a reflexão e o debate em torno destes pontos: qual o impacto que esta decisão terá na prática clínica futura? Como se enquadrará a perspectiva biopsi- cossocial no pós-DSM5? Quais as implicações desta decisão na gestão de Saúde Mental nos Cuidados Primários? Apelamos aos leitores que queiram participar neste debate a enviar à RPMGF os seus comentários.

\section{REFERÊNCIAS BIBLIOGRÁFICAS}

1. Houts AC. Fifty years of psychiatric nomenclature: reflections on the 1943 War Department Technical Bulletin, Medical 203. J Clin Psychol. 2000;56(7):935-67.

2. Kawa S, Giordano J.A brief historicity of the Diagnostic and Statistical Manual of Mental Disorders: issues and implications for the future of psychiatric canon and practice. Philos Ethics Humanit Med. 2012;7:2.

3. Mayes R, Horwitz AV. DSM-III and the revolution in the classification of mental illness. J Hist Behav Sci. 2005;41(3):249-67.

4. Frances AJ, Widiger T. Psychiatric diagnosis: lessons from the DSM-IV past and cautions for the DSM-5 future. Annu Rev Clin Psychol. 2012;8:109-30.

5. Kupfer DJ, Kuhl EA, Wulsin L. Psychiatry's integration with medicine: the role of DSM-5. Annu Rev Med. 2013;64:385-92.

\section{CONFLITO DE INTERESSES}

O autor declara não ter conflito de interesses.

ENDEREÇO PARA CORRESPONDÊNCIA

teixeira.pms@gmail.com 